\title{
AS PERSONAGENS ÂNGELA PRALINI E O AUTOR COMO IMPORTANTES ELEMENTOS DE SEGMENTACCÃO NARRATIVA EM UM SOPRO DE VIDA (PULSAÇÕES) (1999), DE CLARICE LISPECTOR
}

\author{
THE CHARACTERS ÂNGELA PRALINI AND THE AUTHOR AS IMPORTANT \\ ELEMENTS OF NARRATIVE COMPOSITION IN A BREATH OF LIFE \\ (PULSATIONS) (1999), OF CLARICE LISPECTOR
}

Recebido: 09/02/2021

Aprovado: 21/06/2021

Publicado: $30 / 07 / 2021$

DOI: $10.18817 /$ rlj.v5i01.2505

\begin{abstract}
Andressa Thainá Lima Braz Monte ${ }^{1}$ Orcid ID: https://orcid.org/0000-0002-5571-7514 Marcelo de Jesus de Oliveira ${ }^{2}$ Orcid ID: https://orcid.org/0000-0003-0981-2737
\end{abstract}

Resumo: O texto intitulado As personagens Ângela Pralini e o Autor como importantes elementos de segmentação narrativa em um sopro de vida (pulsações) (1999), de Clarice Lispector, tem por objetivo analisar, por via de instrumentos bibliográficos, a atuação das personagens Ângela Pralini e o Autor, ambas apresentadas no romance póstumos da escritora Clarice Lispector. A análise, portanto, é realizada de modo a tornar perceptível como as performances das figuras elencadas, pessoais e intrapessoais, atribuem efeitos de sentido a narrativa e, consequentemente, sustentam a característica primordial da literatura clariciana: o enigmatismo. Para tanto, problematizou-se a figura do narrador-personagem, chamado Autor, estabelecendo-se um contraponto entre ele e sua personagem Ângela Pralini, examinando se o processo de construção dessas personagens tem uma imagem que se constitui um pelo outro, com o desejo de se encontrar.

Palavras-chave: Personagens claricianas. Literatura brasileira; Clarice Lispector.

Abstract: The text entitled The characters Angela Pralini and the Author as important elements of narrative segmentation in a breath of life (pulsations) (1999), by Clarice Lispector, aims to analyze, through bibliographic instruments, the performance of the characters Angela Pralini and the Author, both presented in the novel posthumously by the writer Clarice Lispector. The analysis, therefore, is performed in such a way as to make perceptible how the performances of the figures listed, personal and intrapersonal, attribute effects of meaning to the narrative and, consequently, sustain the primordial characteristic of Clarice literature: enigmatism. To this end, the figure of the narratorpersonage, called Author, was problematized, establishing a counterpoint between him and his character Angela Pralini, examining whether the process of construction of these characters has an image that constitutes one for the other, with the desire to meet.

Keywords: Clarician characters. Brazilian literature; Clarice Lispector.

\section{Introdução}

O livro póstumo Um sopro de vida (Pulsações) (1999), de Clarice Lispector, foi iniciado em 1974 e veio a público em 1978. Escrito "em agonia" (BORELLI, 1981),

\footnotetext{
${ }^{1}$ Graduada em Letras pela Universidade Estadual da Região Tocantina do Maranhão - UEMASUL. E-mail: brazandressa8@gmail.com

${ }^{2}$ Mestre em Letras - UFT; especialista em Literatura Contemporânea - INTERVALE; graduado em Letras Português e Literatura. Atualmente, exerce o cargo de Professor nível III, na Universidade Paulista - UNIP/UNIPLAN, curso de Pedagogia. E-mail: pfmarcelopt@gmail.com
} 
a obra resgata a profundidade emocional e a introspecção que caracteriza a complexidade intelectual da escrita clariceana. Além disso, este romance reprisa o paradoxo existencial vida e morte tão presente em sua obra, designa-se como obra de princípio e fim, uno e múltiplo, enfim, nos guia por vários caminhos conhecidos, ou pouco explorados.

Essa obra foi composta simultaneamente ao romance $A$ hora da estrela (1977), último livro publicado por Clarice. Olga Borelli se envolveu em todo o processo de construção das duas obras, acompanhando a autora nos mínimos detalhes, fazendo desde a anotação dos seus pensamentos, organizando manuscritos e, especialmente, vivenciando cada momento de inspiração da autora. Por este motivo, Ihe foi atribuída a responsabilidade de montar os manuscritos de Clarice e, mais tarde, compartilhou o ofício com seu filho, Paulo Valente.

O enredo de Um sopro de vida (Pulsações) baseia-se na história de um narrador-Autor que cria uma personagem, também escritora, a qual reflete um pouco da sua própria imagem. Ângela Pralini, gerada a partir de um "sopro de vida", escreve em seu livro sua própria história, derrama ali seus devaneios, pensamentos mais íntimos, obscuros, enquanto Clarice Lispector se torna uma espécie de ortônimo, ao passo que o narrador-Autor e Ângela Pralini seriam espécies de heterônimos clariceanos.

Toda e qualquer leitura envolve afinidade para ser motivado a continuar, em relação à obra clariceana, sentimo-nos provocados a enfrentar a leitura dessa obra tão perspicaz e buscar esses caminhos ainda pouco explorados. Assim, neste trabalho, visamos analisar as personagens Ângela Pralini e o Autor e os possíveis efeitos de sentido que os mesmos atribuem a obra. Além de aprofundar discussões sobre as relações existentes entre autor, narrador e personagem a partir do contexto da narrativa seleta. Do mesmo modo, investigar e analisar os efeitos de sentido discursivos que recobrem as imagens de Deus, do espelho e da morte em relação ao narrador-Autor e Ângela Pralini.

É possível perceber a autoria de cada um desses integrantes (Autor, Ângela Pralini, Clarice Lispector e Olga Borelli, quem organizou a obra) na concepção de Um sopro de vida (Pulsações). Todos eles, ao serem criados, desencadeiam questionamentos sobre a relação da ficcionalização ou do imaginário com o real, intensificando a linguagem enigmática e dando a narrativa um caráter desfiado, ou seja, falas formadas por fragmentos de duas vozes, que a princípio, não parecem ter 
ligação. Mas, por vezes, podemos sentir o caos: "restos de uma demolição de alma" (LISPECTOR, 1999, p. 20);

Perante essa divisão, torna-se difícil definir personagens/autores, pois ambos levantam questionamentos sobre os limites entre ser o eu e o outro, revelam na sua escrita uma angústia indescritível, como de quem está insatisfeito. Suas palavras não demonstram medo, mas reflexões sobre o instante da vida, por isso tentam ao máximo registrar o agora em seus pensamentos, de modo que proporciona uma imprevisibilidade.

Mediante a esses questionamentos, somos levados ao problema da pesquisa: de que maneira as personagens Ângela Pralini e o Autor se revelam na construção narrativa da obra clariceana Um sopro de vida (Pulsações) em termos autoficcionais e estruturais como uma pulsão criativa?

\section{O narrador-autor: a gênese da Criação}

"Do pó da terra formou Deus-Jeovah o homem e soprou-lhe nas narinas o fôlego da vida. E o homem tornou-se um ser vivente" (Gênesis 2,7).

"A sombra de minha alma é o corpo. O corpo é a sombra de minha alma. Este livro é a sombra de mim" (Clarice Lispector).

De acordo com Gênesis, Deus cria todo o universo e animais em cinco dias, e no sexto, dedica-se ao que seria a primazia da sua criação: o homem. Nesse ato, Deus moldou o homem a partir do pó da terra e soprou-lhe nas narinas o fôlego de vida, este tornou-se um ser vivente. Seguidamente, o homem sentiu falta de alguém para Ihe fazer companhia, então Deus criou a mulher, ambos "a sua imagem e semelhança". Depois disto, cederam ao desejo da serpente e traíram a confiança de Deus, foram expulsos do paraíso, e então, geraram filhos e filhas. Ainda assim, a imagem e semelhança de Deus é refletida na humanidade, a vida é vista como algo sagrado, onde Deus está presente.

Semelhantemente ocorre em Um Sopro de Vida (Pulsações), o processo de gênese da vida. O enredo da obra discorre sobre este fenômeno: o Autor, assim como Deus, possui o poder de gerar vidas, e assim o faz ao criar sua personagem. Mais um detalhe a ser observado nesse fenômeno é, que ele se dá de maneira cíclica, isto é: Deus (Clarice) cria o Autor, o Autor cria Ângela, e Ângela cria Deus. Já 
o Autor, que pensava estar no controle de tudo, acaba chegando à conclusão que depende de outros para existir, como constatamos a seguir:

\begin{abstract}
[Autor] Foi Deus que me inventou e em mim soprou e eu virei um ser vivente (LISPECTOR, 1999, p. 28).

[Autor] Como eu ia dizendo: foi Deus que me inventou. Assim também eu como nas olimpíadas gregas os atletas que corriam passavam para frente 0 archote aceso - assim também eu uso meu sopro e invento Ângela Pralini e faço-a mulher. Mulher linda (LISPECTOR, 1999, p. 73).

[Autor] Um homem imaginou Deus e fez uma cadeira, nessa cadeira deve estar um pouco de energia desse homem. Tal é o espírito das coisas feitas, coisas vividas. Eu inventei Deus - e não acredito n'Ele. É como se eu escrevesse um poema sobre o nada e me visse de repente encarnado frente a frente o próprio nada. Deus é uma palavra? Se for estou cheio dele: milhares de palavras metidas dentro de um jarro fechado e que às vezes eu abro - e me deslumbro. Deus palavra é deslumbrador (LISPECTOR, 1999, p. 127)
\end{abstract}

O livro de Gênesis tem como tema central a criação do homem, e isso tem uma influência muito grande a cerca de quem Deus é, já que ele passa a ser considerado o Senhor supremo do Universo. Isso não cabe apenas ao livro da Bíblia, mas à obra de Clarice. Em ambos, o homem é gerado do barro e moldado como um vaso, e após o sopro de vida, converte-se em ser vivente. Enquanto no paraíso Adão se sentia sozinho, desejando a companhia de outro, em Um Sopro de Vida (Pulsações) o Autor sente a necessidade de estar com outro.

No lugar de criador, o Autor concebe a personagem Ângela e a tem sob seu domínio. Ele procede como um Deus, mas entende que não está acima do Deus que reconhece como verdadeiro, não entrando em divergência com ele. Conquanto, a capacidade de criar não é reservada apenas a Deus, mas também àqueles que fazem da palavra e da literatura seu meio de expressão. Nesse caso, o Autor sente a necessidade do Outro, então, a existência de Ângela permite que ele reconheça seu Eu na pessoa dela, estabelecendo uma conexão vital por via das palavras. O diálogo entre eles abrange assuntos profusos sobre a existência em si, como a respeito de Deus, e suas experiências com o sagrado. Suas criações, entretanto, não são externas como muitos presumem, mas "vêm de lugar nenhum" (LISPECTOR, 1999, p. 17) denominada inspiração, não loucura, mas "É Deus". Tal lugar parte de uma experiência dele, com ele mesmo, e mais ninguém, é uma viagem completamente só ao seu mundo interno. 
O Autor justifica a criação de Ângela, ainda na primeira parte do livro, quando ela ainda não existia, e a razão, mais uma vez, é que ele sente-se sozinho e incapaz. Isso rememora o fato de Deus ter criado o homem, Ele vivia sozinho, e então gera o homem e a mulher, um necessitando do outro.

\begin{abstract}
Deus não deve ser pensado jamais senão Ele foge ou eu fujo. Deus deve ser ignorado e sentido. Então Ele age. Pergunto-me: por que Deus pede tanto que seja amado por nós? resposta possível: porque assim nós amamos a nós mesmos e em nos amando nós nos perdoamos. E como precisamos de perdão. Porque a própria vida já vem mesclada ao erro (LISPECTOR, 1999, p. 19).
\end{abstract}

Captamos, aqui, a imagem de um Deus solitário e carente, o que não é exatamente ruim, já que essa característica o leva a dependência e ao amor do ser humano, para suprir uma necessidade. Assim como Deus sentiu necessidade de Adão, Adão carece de Eva, para se conectar e se identificar, dessarte, o Autor cria Ângela, "para que talvez, através de nós, eu possa entender essa falta de definição da vida" (LISPECTOR, 1999, p. 19).

Na segunda parte do livro, intitulada $O$ sonho acordado é que é a realidade, o Autor apresenta a sua criação, Ângela, e em seu discurso começa exprimindo que ela refletia ele, como um espelho. Enquanto isso, ele afirma que é uma criatura de Deus "Foi Deus que me inventou e em mim soprou e eu virei um ser vivente" (LISPECTOR, 1999, p. 28), e Ângela começa a se aproximar, sua primeira reação é chorar lamentando ter nascido, pois não queria. Esse pode ter sido o primeiro sentimento em comum entre os dois, pois o Autor diz que "eu tenho a vasta e informe melancolia de ter sido criado. Antes tivesse eu permanecido na imanescença do sagrado Nada" (p. 28), tal e qual Deus, ele tem o poder de decidir o que será, ou não, criado.

Nessa hora, instaura-se um elo entre o Autor e Deus, por disporem a mesma potência, mas a atitude do Autor em deixar Ângela "livre" para ser o que ela quiser, o distingue de Deus, isso porque ele não se sujeitaria ao ofício de juiz e julgar as pessoas por suas condutas, sendo diferente de um Deus autoritário, ele opta pela autonomia. Mas Ângela não compreende isso, pois, assim como cada um tem uma visão diferente sobre muitas coisas, ela não enxerga Deus da mesma forma que o Autor. 
Finalmente Ângela ganha voz na narrativa, o discurso se mantém fragmentado, e vão se intercalando, mas o Autor continua preeminente, está sempre ao redor observando, complementando ou contraponto o que Ângela diz. A verdade que ele mesmo afirma é "Até onde vou eu e em onde já começo a ser Ângela? Somos frutos da mesma árvore? Não - Ângela é tudo que eu queria ser e não fui" (LISPECTOR, 1999, p. 30). Ele fica inquieto em poder agir como Deus, de a qualquer momento poder interferir na vida de Ângela "Quando penso que eu poderia fazer com que ela morresse, estremeço todo" (LISPECTOR, 1999, p. 57), mas ainda assim se contém, não se sente confortável para se intrometer, pois começa a gostar da sua desenvoltura. Criado por Deus e criador de Ângela, o Autor compreende que a sua vida está sujeita aos dois para fazer sentido, e que o propósito da vida é outrar-se ${ }^{3}$.

Podemos perceber a plenitude buscada por Joana em Perto do coração selvagem (1943) e G.H., em A paixão segundo G.H. (1964), perceptível em Um Sopro de Vida (Pulsações) (1999). Conquanto, ao contrário de Joana, que evoca o outro (Deus) em sua prece de desespero, e G.H., que reza pelo afastamento do outro (de Deus) para que ela possa se encontrar, Ângela tem uma experiência inigualável, quase física, com Deus, sentia-se completamente plena e preenchida por ele em "estado de graça", diferentemente do Autor, que mesmo reconhecendo que a prece o leva até Deus, distingue que o seu "estado de graça" está em compreender que Deus está dentro dele e não fora.

Ângela pensa que estado de graça ou de vida está em realizar-se no mundo externo. Mesmo Deus ela se força a conquistar, tornando-o o mundo externo. Mas quem vive em estado de graça, não permanentemente mas com muita frequência, sou eu. Consegui isto através de um desapego em relação ao mundo. Vivo um vazio que se chama também plenitude. Não ter me cumula de bênçãos. Quanto à minha vida prática consegui viver em cidade grande e turbulenta como se ela fosse provinciana e fácil (LISPECTOR, 1999, p. 82).

\footnotetext{
${ }^{3}$ Fenómeno de fazer-se outro, de adotar várias personalidades, dando-Ihes vida e independência. Outrar-se pode ser, também, definido, como deixar-se contagiar por algo de sentido novo e diferente (por exposição a culturas, climas, linguagens, pensamentos...), deixando-se transformar num ser novo, distinto, que veste uma nova personalidade ou forma de estar no mundo. A heteronímia de Fernando Pessoa, enquanto forma extrema de despersonalização, revela este fenómeno de outrarse. A tendência para ser outro levou Fernando Pessoa a tornar-se criador e administrador de "eus" com personalidade própria, com estilos próprios e diferentes dos demais, com biografias distintas, como revela quando fala da sua heteronímia.
} 
Refletindo sobre todos esses processos entre o Autor e Ângela, tanto a experiência do eu, quanto a de Deus, só são exequíveis, se primeiro houver a experiência do outro, por consequência, a experiência de si mesmo.

O Autor fala sobre seu contínuo processo de transformação, e diz que vive "em eterna mutação, com novas adaptações a meu renovado viver e nunca chego ao fim de cada um dos modos de existir", recapitula o caráter descontínuo do livro quando afirma que "vive de esboços não acabados e vacilantes" (LISPECTOR, 1999, p. 86), mas procura o equilíbrio entre as pessoas e Deus.

Quando ele chega nesse ponto, remete a uma série de questionamentos sobre alma, existência, passado, presente e futuro. Já nas primeiras páginas do livro ficamos cientes da sua particularidade, ou melhor, descontinuidade.

\footnotetext{
Minha vida é feita de fragmentos e assim acontece com Ângela [...] O que escrevo aqui, meu ou de Ângela, são restos de uma demolição de alma, são cortes laterais de uma realidade que me foge continuamente. Esses fragmentos de livro querem dizer que eu trabalho em ruínas (LISPECTOR, 1999, p. 20).
}

Esse trecho apresenta uma mensagem impactante, de tal modo que podemos sentir ou imaginar o estado em que se encontra a alma das personagens. $O$ desejo do Autor é atendido quando ele diz "Quero que cada frase desse livro seja um clímax" (LISPECTOR, 1999, p. 16), então o livro nos faz experimentar o sentimento emanando de cada palavra. Nele nos é negada a expectativa de homogeneidade, por isso não devemos procurar um sentido, mas vivenciar com ele cada instante. Nesse sentido, Castro e Lo Bianco (2009, p. 91), em seu artigo A disciplina de leitura: ritmo e oralidade na $v o z$ do Texto recomendam uma leitura amparada na identificação de "traços específicos, sem buscar compreendê-los cedo demais, uma leitura que não implica competência linguística e na qual está em jogo a posição do sujeito em relação à sua própria linguagem".

Essa fragmentação no discurso, que dificulta um tanto quanto a compreensão por parte do leitor, está intimamente ligada à ideia atemporal que é pregada no livro, como outrora citado, a obra não constitui uma trama com início, meio e fim, suas partes chegam a ser independentes, mas, paradoxalmente, dependentes, formando um ciclo que se fecha, como na figura de uma cobra que come o próprio rabo, já que "o fim, que não deve ser lido antes, se emenda num círculo ao começo" (LISPECTOR, 1999, p. 19). Aqui, entra em questão a temporalidade, que pode ser 
elucidado por Castro \& Lo Bianco (2009, p. 93) em: "Trata-se de um tempo paradoxal sobre cujas cenas apenas depois de acontecidas reconhecemos que terão ocorrido desde o início", ou seja, a escrita só é discernida em algum momento depois durante a leitura.

Ainda identificamos outros pontos relativos à temporalidade. Lucia Castelo Branco faz uma alusão entre o título do livro com a epígrafe de Gênesis 2;7 indicando uma relação entre o movimento da narrativa sem que seja possível delimitar uma origem:

Entretanto, esse sopro de vida fundador, originário, produtor de novas palavras e novos sentidos, não se demarcar nesse texto de Clarice, como a origem, a fundação, a matriz, como poderia sugerir uma leitura apressada do Gênesis, cuidadosamente escolhido para a epígrafe [...] O sopro de vida é antes o que não começa pelo princípio, mas o meio, antes o que não começa pelo dentro, mas pelo fora (o "fora de si", o "exterior), o que faz do texto uma escrita em constante processo, em incessante movimento, o que não para de soprar e sussurrar estranhos sentidos, inesperados nadas na orelha do leitor (CASTELO BRANCO, 2004, p. 213, grifos no original).

A obra parece marcar temporalidades distintas, como a separação entre a passagem do tempo cronológico e o tempo de escrever. Esse tempo de escrever, em particular, pode ser testificado por meio do texto subsequente: "Minha vida é um único dia. E assim que o passado me é presente e futuro. Tudo numa só vertigem" (LISPECTOR, 1999, p. 18) e "tudo se passa exatamente na hora em que está sendo escrito e lido" (1999, p. 20). Assim, comprova-se que há uma fragmentação na própria temporalidade, e tal característica é destacada por (ROSENFELD, 2002, apud PRELORENTZOU, 2017, p. 215) como uma das marcas do romance moderno.

A escrita tem um movimento complexo de aproximação e distanciamento do eu "Quero escrever movimento puro". Nas passagens "Será horrível demais querer se aproximar dentro de si mesmo do límpido eu? [...] é quando o eu passa a não existir mais, a não reivindicar nada, passa a fazer da árvore da vida - é por isso que luto para alcançar" (LISPECTOR, 1999, p. 15) e "Solto minhas amarras: mato o que me perturba e o bom e ruim me perturbam, e vou definitivamente ao encontro de um mundo que está dentro de mim, eu que escrevo para me livrar da carga difícil de uma pessoa ser ela mesma" (LISPECTOR, 1999, p. 17), essa aproximação do eu é marcada por um distanciamento paralelo, dado que ocorre a aproximação na intenção de se livrar do peso de ser ele mesmo. 
O resultado disso tudo é que eu vou ter que criar um personagem - mais ou menos como fazem os novelistas, e através da criação dele para conhecer. Porque eu sozinho não consigo: a solidão, a mesma que existe em cada um, me faz inventar. E haverá outro caminho de salvar-se? senão o de criar as próprias realidades? (LISPECTOR, 1999, p. 19).

O Autor dá a vida a Ângela, para, logo após, ser substituído por ela, na autoria e nas reticências. Como sugere o encerramento da obra, o Autor anuncia a própria morte para em seguida partir, e outro narrador, não apresentado até o momento, declara:

[quando o olhar dele vai se distanciando de Ângela e ela fica pequena e desaparece, então o Autor diz:] - Quanto a mim também me distancio de mim. Se a voz de Deus se manifesta no silêncio, eu também me calo silencioso. Adeus (LISPECTOR, 1999, p. 159).

Nesse trecho deparamos as duas vertentes quanto ao tempo: em primeiro, o tempo que "não se conta" (atemporal), caracterizado pelo instante fragmentado, que não corre, ou corre em câmera lenta, habitando nele uma eternidade; segundo, o tempo "cronológico", que conta literalmente sua marcação, demarcando o limite, trazendo o sentido de morte. Nesse momento, é inevitável lembrarmos que a própria autora, Clarice Lispector, estava perto da morte, sentindo esse tempo escoar por entre as mãos.

Por fim, recordamos da sua última entrevista concedida à TV Cultura (1977), após a publicação de $A$ hora da estrela (1977) e pouco antes de sua morte, em que ela disse: "Quando não escrevo estou morta".

\section{Ângela Pralini: o sonhar acordado, reflexo, imagem e semelhança}

A segunda e a terceira parte do livro intituladas: $O$ sonho acordado é que é a realidade e Como tornar tudo um sonho acordado?, respectivamente, carregam consigo uma concepção incompreensível da realidade, e nisso é apresentado o caráter enigmático da escrita. Na segunda parte, precisamente, se dá a criação de Ângela, onde, o Autor introduz: "Tive um sonho nítido inexplicável: sonhei que brincava com o meu reflexo. Mas meu reflexo não estava num espelho, mas refletia uma pessoa que não eu" (LISPECTOR, 1999, p. 27). Até então, foi bem esmiuçada a falta de racionalidade do livro, e aqui, mais uma vez confirmamos com a ausência de concordância entre o sonho do Autor e a realidade. $O$ texto começa a sugerir algo 
utópico, que não é palpável. Outro quesito a ser levado em conta, é o aparecimento insólito de outra pessoa no reflexo do Autor, enquanto ele olhava para o espelho. Sinteticamente, o que sucede nesse primeiro parágrafo, é que Ângela foi criada através desse sonho, e nela habita o reflexo do Autor, o Outro.

Há muitos estudos no ramo dos sonhos que afirmam termos pelo menos duas horas por noite neste universo onírico, que é um meio de conhecimento sobre nós. Freud, grande médico psicanalista, se dedicou muito aos estudos nessa área, e diz que a interpretação dos sonhos é de grande valia para obter os conhecimentos mais profundos sobre uma pessoa, para ele, o sonho é a expressão de algum sentimento que foi reprimido.

Se associarmos esse breve conceito do sonho à obra clariceana, chegaremos a algumas importantes conclusões, como sobre a nomeação dos títulos da segunda e terceira partes do livro, que revelam o desejo de a vida ser sonho, e para o Autor, esse sonho ser realizado em Ângela.

Segundo Freud, existem dois procedimentos do sonho que são materializados para que esse desejo seja cumprido: o deslocamento e a condensação. $O$ deslocamento identifica-se nos três processos da narrativa: de Clarice para o Autor, do Autor para Ângela, e de Ângela para Clarice. Na condensação, fica claro quando percebemos que eles são um só: "- Ângela. - [...] No meu livro A cidade sitiada eu falo indiretamente no mistério da coisa." (LISPECTOR, 1999, p. 104).

Retomando a significação do espelho no fragmento supracitado, torna-se propício discorrer mais sobre o discurso de Clarice, no sentido de esclarecer as associações entre a autora e suas personagens: “-[...] Por causa desse sonho é que inventei Ângela como meu reflexo? Tudo é real mas se move va-ga-ro-sa-mente em câmera lenta. [...] com o equivalente a milhares de transistores microscópicos gravados em sua superfície polida e faiscante com o sol a pino num espelho, Ângela é um espelho" (1999, p. 27-28).

Recorremos a Bakhtin que explica este entendimento:

Contemplar a mim mesmo no espelho é um caso inteiramente específico de visão da minha imagem externa. Tudo indica que neste caso vemos a nós mesmos de forma imediata. Mas não é assim; permanecemos dentro de nós mesmos e vemos apenas o nosso reflexo, que não pode tornar-se elemento imediato da nossa visão e vivenciamento do mundo: vemos o reflexo da nossa imagem externa, mas não a nós mesmos em nossa imagem externa; a imagem externa não nos envolve ao todo, estamos diante e não dentro do espelho [...] (BAKHTIN, 2003, p. 30). 
O que Bakhtin trata é do sentido literal de olharmos somente, nada mais além do nosso reflexo quando olhamos para o espelho, nele não está a nossa essência, quem somos, o que sentimos, nossas experiências etc., mas, apenas a representação estética. No caso do Autor, podemos presumir que ele viu o que desejava ser, mas não era, não necessariamente uma outra pessoa, mas os seus desejos reprimidos. Ângela é o reflexo do Autor, que é o reflexo de Clarice. “-[...] eu não estou só quando me contemplo no espelho, estou possuído por uma alma alheia [...]" (BAKHTIN, 2003, p. 31).

Embora o Autor afirme não saber o que esperar da sua criatura, o diálogo entre eles se conecta a partir dessa ligação - criador/criatura, espelho/reflexo - as escritas de ambos entram em sintonia com o Nada, e em meio aos devaneios dessa escrita, Ângela parece sonhar acordada, pois é o sonhar acordado com o Autor.

Ângela é festa de nascimento. Não sei o que esperar dela: terei que transcrevê-la? Tenho que ter paciência para não me perder dentro de mim: vivo me perdendo de vista. Preciso de paciência porque sou vários caminhos, inclusive o fatal beco sem saída. Sou um homem que escolheu o silêncio grande. Criar um ser que me contraponha é dentro do silêncio [...] Ângela é mais do que eu mesmo. Ângela não sabe que é personagem. Aliás eu também talvez seja o personagem de mim mesmo. Será que Ângela sente que é personagem? Porque quanto a mim, sinto que de vez em quando sou o personagem de alguém. É incômodo ser dois: eu para mim e eu para os outros. Eu moro na minha ermida de onde apenas saio para existir em mim: Ângela Pralini (LISPECTOR, 1999, p. 29).

Essa obra é repleta de metáforas e, especialmente, paradoxos. A personagem Ângela, que desperta no Autor sentimentos estranhos, é imprevisível. Pertence ao Autor, mas é um meio de fuga e uma oportunidade de encontrar-se; por hora parecem repelir um ao outro, mas o texto vai revelando a sintonia entre eles, como o sonhar acordado, é tanto que o próprio Autor não consegue desassociar um do outro: "Até onde vou eu e onde já começo a ser Ângela? Somos frutos da mesma árvore? Não - Ângela é tudo o que eu queria ser e não fui. O que é ela? Ela é ondas do mar. Enquanto eu sou floresta espessa e sombria" (LISPECTOR, 1999, p.30). É tamanha a amálgama, mas entre eles também há disparidades, Ângela é graciosa e leve, o Autor, enclausurado; Ângela é "uma curva em interminável sinuosa espiral" (1999, p. 44), o Autor se autodenomina reto. Com todas as dessemelhanças, o Autor 
diz ser Ângela tudo o que ele queria ser, mas não era, e ela não poderia ser outra coisa, senão o seu oposto.

Ângela é muito parecida com o meu contrário. Ter dentro de mim o contrário do que sou é em essência imprescindível: não abro mão de minha luta e de minha indecisão e o fracasso - pois sou um grande fracassado - o fracasso me serve de base para que eu existir. Se eu fosse um vencedor? Morreria de tédio. "Conseguir" não é meu forte. Alimento-me do que sobra de mim e é pouco. Sobra, porém, um certo secreto silêncio (LISPECTOR, 1999, p. 46).

Algumas vezes o Autor recomenda que ele tire férias e Ângela o substitua. $\mathrm{O}$ Autor começa a estimá-la afirmando: "Ela é as palavras que eu esqueci" (1999, p. 58), Ângela é sua personagem mais delicada, porém, mais intensa que chega lhe sobrepujar, e o faz indagar se ela era apenas uma personagem ou uma "demonstração de vida além-escritura, como além-vida e além-palavra" (1999, p. 34). Esse posicionamento dá a Ângela maior prestígio diante de seu criador enclausurado, ele a incentiva a expressar mesmo que não faça sentido, ele a deixa ser.

Por entre as divagações da escrita, Ângela começa a falar sobre "criar silêncios": "ligo o rádio bem alto - então de súbito desligo. E assim capto o silêncio. Silêncio estelar. O silêncio da lua muda. Para tudo: criei o silêncio. No silêncio é que mais se ouvem ruídos. Entre as marteladas eu ouvia o silêncio" (1999, p. 55). Ela se detém no intervalo dos sons que aparecem, o que aponta para um novo tipo de fragmentação, ela ouve a voz do silêncio em meio ao barulho, e não o oposto. Para ela, o silêncio é a sua sinfonia, o silêncio fala tanto como a música, o rádio, os instrumentos. Ângela parece sempre estar em uma linha muito tênue entre os opostos. As palavras são tão poucas para lhe expressar, que a faz ouvir o silêncio, ela está além, quase no precipício de tudo que sente e faz, como expressa o comentário de Castelo Branco:

Além escritura, além vida, além palavra. Além- corpo, pode-se acrescentar. O que além do corpo? $O$ sopro. O que há além da palavra? $O$ silêncio. $O$ que há além da vida? A morte. A respeito desses sinistros lugares do nada e do vazio, fala-nos este texto invocatório de Clarice. [...] do que está para além da linguagem, mas só através da linguagem pode ser pensado, do que é ilimitado, indizível, impossível, mas através dos limites e das possibilidades do discurso viria a ser sugerido (CASTELO BRANCO, 2004, p. 213). 
No momento em que Ângela pergunta "O que eu escrevo está sem entrelinha? Se assim for, estou perdida" (LISPECTOR, 1999, p. 96), ela mesma responde deixando isso claro, o que ela diz, ou não diz, tem uma causa e efeito. Seus escritos possuem um "sentido", entrelinhas, mesmo o silêncio, ou ausência de palavras.

No instante em que a personagem consegue discernir seus objetos e coisas, ela obtém uma ótica que a faz ter uma concepção a respeito da criação e existência: "Se eu fosse Deus eu veria o homem, à sua distância, como coisa. Nós somos de uma fabricação divina" (1999, p. 115). Este é o ápice do livro, pois concerne a uma questão crucial, que não tem a ver com a "se Deus existisse...", mas "se eu fosse Deus...", pois está evidente Sua existência. Entretanto, há o conflito entre/nas personagens, e nisso elas são semelhantes, já que todas podem criar o ser humano.

\section{Considerações finais}

Clarice Lispector, sem dúvida, marcou sua época ao traspassar os padrões das teorias literárias, quiçá, ainda hoje consegue transcender muitas barreiras, porque ela está muito à frente do seu e do nosso tempo. Não há como restringi-la, classificá-la ou delimitá-la. Em Um sopro de vida (Pulsações) (1999), Clarice é duo, é Ângela, é o Autor. Ângela não tem amarras, é livre, mística, inconsequente. E o Autor, enclausurado, escreve um livro e incentiva sua personagem a escrever outro, e assim como Clarice, Ângela "Só consegue anotar frases soltas (...). Amanhã eu começo o meu romance das coisas" (LISPECTOR, 1999, p 102).

A autora parece contraditória, pois se sente amedrontada diante de uma folha em branco, talvez por se sentir forçada a criar, quando ela só conseguia escrever quando a "coisa vinha", de forma fragmentada, em restos de papeis. Provavelmente, a sua alma parecia devastada no momento em que escreveu essa obra, sugerindo a forma que foi feita, em pedaços.

A fim de enlaçar a leitura desse romance, podemos, a partir deste final, concluir que a escritura clariceana tem suas singularidades, e é diferente de muitas outras que estamos habituados. Embora desenvolvam-se muitas teorias a fim de interpretá-la, nela, como a própria autora declara, não podemos buscar por respostas racionais, apenas "sentir". 
O texto de Clarice possui uma rica temática, das quais, o vazio presente nas palavras e o desprendimento de si demonstrado na escrita, despertaram a atenção para o pontapé inicial desta pesquisa, assim como sua originalidade e mistério, que fazem com que se destaque entre muitos artistas. Falar de Clarice é uma tarefa complexa, uma vez que a mesma não conseguia falar de si própria, mas propomos, sob olhares críticos e entendedores da área, abordar sobre o universo em que ela estava inserida. Em seguida, descrever a peculiaridade que é a escrita clariceana. Ela demonstra maestria no uso das palavras, apresentando, mesmo hoje, algo inovador, pois sua linguagem institui uma nova concepção de tempo para o romance. Sentimos nessa linguagem que a autora se valia de seu trabalho como se fosse uma válvula de escape, como vimos no exemplo do Autor, uma fuga de si mesmo para encontrar-se.

Clarice, à sua maneira, tenta expressar-se, mas para muitos não é compreensível, ou muitos simplesmente não se permitem entender. Nunca saberemos se é puramente verídico, mas, se Clarice se expressava por fragmentos em processos de epifanias, talvez suas personagens fossem várias facetas da mesma mulher, muitas faces de um único EU, uma personagem real, cujo interior sentia, absorvia, se emocionava, demonstrava sensibilidade para com o outro e o mundo.

Muitas de suas personagens durante toda uma carreira tinham características similares a ela ou coisas em comum, como seu cachorro Ulisses, por quem tinha enorme afeto. Ulisses, que em Quase de verdade (1978), lançado postumamente, conta uma história uma história para sua dona, Clarice "ela se propõe a falar por Ulisses e escreve - Au, au, au!" (MANZO, 2001, apud LISPECTOR, 2011, p.187).

Clarice em sua escrita não se detinha apenas à estética normativa, mas sim a busca da linguagem como tradução de sentimentos e experiências. Mesmo à beira da morte, às 10h20min do dia nove de dezembro de 1977, tentou escapar, levantouse da cama em desespero e caminhou em direção à porta, queria fugir do quarto. Uma enfermeira a impediu e a escritora então esbravejou: "Você matou meu personagem" (MANZO, 2011, p. 222). Ângela e o Autor se despedem na última página de Um sopro de vida (Pulsações) (1999) de uma forma única, meio enigmática, como sempre, mas revelando a continuidade do livro: "Não posso acabar. Eu acho que..." (LISPECTOR, 1999, p. 159). Desde o prefácio o Autor diz que se trata de "um livro silencioso", "um livro fresco recém-saído no nada" (1999, 
p.16), e como vimos outrora, o fim do livro se liga ao início, ele se dá com uma frase que não está encerrada, e com o desaparecimento de Ângela.

Em Um sopro de vida (Pulsações) (1999) além do modo particular e inovador em que se constrói a narrativa, sua escrita estimula a imaginação do leitor, por meio de sua complexidade, pensamentos e emoções profundas, a pensar sobre sua própria existência, sobre sua transitoriedade e a efemeridade das coisas. Sua escrita traz consigo o que está além da palavra: a experiência. A escrita de Um sopro de vida (Pulsações) (1999) está relacionada ao abstrato e é uma cilada para os pensamentos do leitor. Uma experiência de linguagem nos dá a oportunidade de arriscar-nos como uma dimensão vazia frente à infinidade da língua e sua potência enquanto criadora de significados.

"Pulsações", no título da obra, carrega a essência da vida, como os batimentos cardíacos que é nossa primeira manifestação vital. Vimos a obra ser marcada pelo processo de criação - gênese - da vida humana, de uma personagem e das palavras, cada uma com seus dilemas e inquietações, todas necessitando de algo para existir ou encontrar-se. Um sopro de vida (Pulsações) (1999) nos faz meditar sobre a cada instante estarmos morrendo e renascendo, continuamente em "movimento puro" de gênese e extinção. Clarice Lispector nos concedeu mais que uma narrativa ou um texto, ela nos outorga um coração com percepção profunda do que somos.

\section{Referências Bibliográficas}

BORELLI, Olga. Clarice Lispector, Esboço para um possível retrato. Rio de Janeiro, 1981.

BRANCO, Lucia Castelo. Todos os sopros, o sopro. In: Vera Queiroz (org). Revista Tempo brasileiro: Clarice e o feminino. Rio de Janeiro: Tempo brasileiro, n. 104, p. 58,1991 .

CASTRO, Juliana de Miranda e LO BIANCO, Anna Carolina. A disciplina de leitura: ritmo e oralidade na voz do texto. Vol.21, no.spe, p.89-94. ISSN 0102-7182 Psicol. Soc., 2009.

LISPECTOR, Clarice. A hora da estrela. José Olympio, 1977.

. A paixão segundo G.H., Editora do Autor, 1964.

Descoberta do mundo. Rio de Janeiro: Rocco, 1999. 
. Entrevista à Julio Lerner. TV Cultura. São Paulo, fevereiro de 1977.

Janeiro: Rocco, 2005

. Perto do coração selvagem. A noite, 1943.

. Um sopro de vida (pulsações). Rio de Janeiro: Rocco, 1999.

MANZO, Lícia. Era uma vez: EU. A Não-ficção na obra de Clarice Lispector. Curitiba: UFJF- Templo Gráfica, 2001.

PRELORENTZOU, Renato. A personagem de autoficção: anotações de uma hipótese para textos futuros. Letras de Hoje, Porto Alegre, v. 52, n. 2, p. 214-223, abr.-jun. 2017. 